\title{
Bacterial Spectrum and Antibiotic Resistance Patterns of Ocular Infection: Differences between External and Intraocular Diseases
}

\author{
Nan Wang, Qian Yang, Yiwei Tan, Liping Lin, Qiang Huang, and Kaili Wu \\ Zhongshan Ophthalmic Center, State Key Laboratory of Ophthalmology, Sun Yat-Sen University, Guangzhou 510060, China \\ Correspondence should be addressed to Kaili Wu; wukaili@mail.sysu.edu.cn
}

Received 18 June 2015; Accepted 30 September 2015

Academic Editor: Edward Manche

Copyright (C) 2015 Nan Wang et al. This is an open access article distributed under the Creative Commons Attribution License, which permits unrestricted use, distribution, and reproduction in any medium, provided the original work is properly cited.

This study aimed to compare the differences of microbial spectrum and antibiotic resistance patterns between external and intraocular bacterial infections in an eye hospital in South China. A total of 737 bacteria isolates from suspected ocular infections were included in this retrospective study covering the period 2010-2013. The organisms cultured from the ocular surface (cornea, conjunctiva) accounted for the majority of the isolates $(82.77 \%, n=610)$, followed by the intraocular (aqueous humor, vitreous fluid), which accounted for $17.23 \%(n=127)$. The top three species accounting for the external ocular infections were $S$. epidermidis (35.25\%), P. aeruginosa (8.03\%), and S. simulans (4.43\%). The top three species for the intraocular infections were S. epidermidis (14.96\%), S. hominis (8.66\%), and B. subtilis (7.87\%). The bacteria from the external ocular surface were more sensitive to neomycin, while those from the intraocular specimens were more sensitive to levofloxacin $(P<0.01)$. Multidrug resistance was found in 89 bacteria (12.08\%), including isolates from both external (13.28\%) and intraocular samples (6.30\%). The results of this study indicate that the bacteria spectrum of external and intraocular infections is variable in the setting. A high percentage of bacterial organisms were found to be primarily susceptible to neomycin for external infection and levofloxacin for intraocular infection.

\section{Introduction}

Ocular bacterial infections can cause a series of symptoms and signs, such as the formation of pus, conjunctival hyperemia, lid edema, and even visual impairment. The causative bacteria can come from the outside environment or from systemic infections transported by blood. The eyelid and conjunctiva have normal bacterial flora, of which disequilibrium facilitates external or intraocular infection $[1,2]$. Bacteria of the normal microbiome can also cause infection, especially when they enter the aqueous humor or vitreous fluid.

There have been many reports on the bacterial profile and antibiotic susceptibility of ocular infections, with varying results between cases [3-6]. For example, an original report from Japan analyzed the culture-positive rate and the prevalence of drug resistance among microorganisms isolated from discharges, corneal and conjunctival tissues, vitreous fluid, or aqueous humor of patients with ocular infections over a 4-year period [4]. Consequently, the major pathogen strains were gram-positive (GP) bacteria (Staphylococcus spp. mainly), and the levofloxacin-resistant strains accounted for $32.8 \%$ [4]. Bharathi and colleagues from South India reported that, of 4,417 ocular samples (from infections of the eyelid, conjunctiva, lacrimal apparatus, cornea, intraocular tissues, orbit, and sclera), the culture-positive rate of bacteria was $58.8 \%$, with GP cocci being the most frequent bacteria isolated from ocular infections, which were sensitive to moxifloxacin (98.7\%) and vancomycin (97.9\%), while gramnegative (GN) isolates were more sensitive to amikacin (93.5\%) and gatifloxacin (92.7\%) [5]. In the New York Eye and Ear Infirmary, Adebayo and colleagues reviewed 12 years of data from their hospital and found that, among 20,180 conjunctival bacterial cultures, $60.1 \%$ were culture-positive and $S$. aureus was the most common pathogen; in addition, moxifloxacin and gatifloxacin currently appear to be the best choice for empirical broad-spectrum coverage [7]. Additionally, other reports on the ocular bacterial infection and antibiotic susceptibility have been reported in the literature from various countries, like Colombia [8], Pakistan [9], Italy [10], and Uganda [11], among other locations. 
The intraocular infection, for example, bacterial endophthalmitis, is a common and serious condition that frequently leads to visual impairment and can even cause blindness [12]. A number of studies have demonstrated that the bacterial profile of endophthalmitis is different from the causative pathogens of ocular surface infection. Benz and colleagues from Miami reported that the most common organism identified in the vitreous fluid of endophthalmitis patients was S. epidermidis (27.8\%) [13], while a report from London showed that the most common organism in the endogenous bacterial endophthalmitis is $S$. aureus [14]. In addition to the reports from various locations, limited data from the same hospital also clearly showed that the bacterial flora that infected the ocular surface was different from the pathogen bacteria of endophthalmitis $[5,6]$.

These different results, including the change of bacterial spectrum, have been attributed to the region and environment, as well as seasonal changes $[15,16]$. To better understand the differences of bacterial profiles and resistance patterns between external and intraocular infections in South China, the present study retrospectively investigated and analyzed ocular isolates obtained from patients with suspected ocular infections. Additionally, the in vitro susceptibility of bacterial isolates from different ocular sites to eight antibiotics was assessed to provide guidance for clinical treatment.

\section{Materials and Methods}

A retrospective review was conducted on patients (outpatients and inpatients) who were suspected of having ocular infections based on their clinical findings and had undergone further microbiological evaluation at Zhongshan Ophthalmic Center, Guangzhou (northern latitude $23^{\circ} 6^{\prime \prime}$, eastern longitude $113^{\circ} 15^{\prime \prime}$ ), between January 2010 and December 2013, while patients either suspected or having a positive culture of viral, fungal or Acanthamoeba infection were excluded. This study was performed in compliance with the principles of the Declaration of Helsinki and was approved by the Institutional Ethics Committee of Zhongshan Ophthalmic Center, Sun Yat-Sen University.

2.1. Bacterial Isolation and Identification. Samples were taken from diseased tissues (i.e., cornea, conjunctiva, aqueous humor, and vitreous fluid) from all patients with suspected ocular infections (for ocular surface sampling, topical anesthesia by $0.5 \%$ proparacaine hydrochloride). All protocols were conducted as previously reported $[17,18]$. Briefly, specimens of conjunctival sacs were collected by sterile cotton swabs; cornea specimens were sampled by scraping the base and edges of the ulcerated part of the cornea with a sterile special knife; anterior chamber fluids were aspirated through the limbus using a needle on a $1 \mathrm{~mL}$ syringe and vitreous specimens were obtained through the pars plana prior to antibiotic injection or vitrectomy. And then the collected samples were inoculated in nutrient broth overnight at $37^{\circ} \mathrm{C}$. Subsequently, the broth was inoculated onto sheep blood agar for bacterial culture. The cultures were considered to be positive as Bourcier et al. reported [19], and bacteria isolates were identified using an automated microbiology system (Vitek 2 Compact, BioMerieux, Inc., Durham, NC, USA).

2.2. Antibiotic Susceptibility Test. Antibiotic susceptibility testing of isolated bacteria was performed in vitro on ceftazidime $(30 \mu \mathrm{g})$, cefuroxime $(30 \mu \mathrm{g})$, cefazolin $(30 \mu \mathrm{g})$, levofloxacin $(5 \mu \mathrm{g})$, ofloxacin $(5 \mu \mathrm{g})$, neomycin $(30 \mu \mathrm{g})$, tobramycin $(10 \mu \mathrm{g})$, and chloramphenicol $(30 \mu \mathrm{g})$ using the Kirby-Bauer disc diffusion method. Bacterial susceptibilities were recorded as "resistant," "intermediate," and "sensitive." The antibiotic susceptibility was determined in accordance with the methods of the Clinical and Laboratory Standards Institute (CLSI). For the purpose of the study, "intermediate" and "sensitive" were both considered sensitive.

2.3. Statistical Analysis. The statistical analysis was performed using SPSS 17.0 (Chicago, IL, USA). The Chi-square test was employed for the comparison of categorical variables. Differences were considered to be significant at $P<0.05$.

\section{Results}

A total of 3,040 samples from the suspected external and intraocular infections were cultured at our institution during the study period. Among the collected samples, 737 had culture-positive bacteria (Table 1). Of these isolates, the organisms cultured from the ocular surface (cornea, conjunctiva) accounted for the majority $(82.77 \%, n=610)$, followed by the intraocular (aqueous humor, vitreous fluid), which accounted for $17.23 \%(n=127)$. The culture-positive rates for intraocular infections and the ocular surface were $19.21 \%(127 / 661)$ and $25.64 \%(610 / 2379)$, respectively. When the culture-positive rates of four types of samples were assessed, the highest rate was found in conjunctiva $(48.85 \%$; 213 of 436), followed by vitreous fluid (21.80\%; 92 of 422), cornea $(20.43 \%$; 397 of 1943$)$, and aqueous humor $(14.64 \%$; 35 of 239). The GP bacteria were the most prominent pathogen for external and intraocular infections (78.36\% and 69.29\%, resp.). The top three species for the external ocular infections were S. epidermidis $(35.25 \%, n=215)$, P. aeruginosa $(8.03 \%$, $n=49)$, and $S$. simulans $(4.43 \%, n=27)$. Specifically, the main causative organisms for cornea and conjunctiva infections were all Staphylococcus spp. The top three species for the intraocular infections were $S$. epidermidis $(14.96 \%$, $n=19)$, S. hominis $(8.66 \%, n=11)$, and B. subtilis $(7.87 \%$, $n=10)$.

A comparison of the antibiotic resistance of external and intraocular bacteria to ceftazidime, cefuroxime, cefazolin, levofloxacin, ofloxacin, neomycin, tobramycin, and chloramphenicol was shown in Figure 1(a). Generally, among five antibiotics that are present in eye drop products in China, the bacteria found in the external ocular were more sensitive to neomycin, while bacteria from intraocular isolates were significantly more sensitive to levofloxacin than to neomycin $(P<0.01)$. Meanwhile, for the cephalosporins, the intraocular isolates showed a high sensitivity to ceftazidime. There were significant differences in resistance to levofloxacin and chloramphenicol between external and intraocular isolates $(P<0.05)$. The antibiotic resistance of $S$. epidermidis in both 
TABLE 1: Bacterial isolates recovered from external and intraocular infections.

\begin{tabular}{|c|c|c|c|c|c|c|}
\hline & \multicolumn{2}{|l|}{ External ocular isolates } & \multicolumn{2}{|l|}{ Intraocular isolates } & \multicolumn{2}{|c|}{ Total } \\
\hline & Number (cornea, conjunctiva) & $\%$ & Number (aqueous humor, vitreous) & $\%$ & Number & $\%$ \\
\hline Gram-positive organisms* & $478(294,184)$ & 78.36 & $88(24,64)$ & 69.29 & 566 & 76.8 \\
\hline Staphylococcus spp. & $376(223,153)$ & 61.64 & $55(15,40)$ & 43.31 & 431 & 58.48 \\
\hline Kocuria spp. & $27(21,6)$ & 4.43 & $4(1,3)$ & 3.15 & 31 & 4.21 \\
\hline Micrococcus spp. & $5(5,0)$ & 0.82 & 0 & 0.00 & 5 & 0.68 \\
\hline Bacillus spp. & $8(5,3)$ & 1.31 & $10(3,7)$ & 7.87 & 18 & 2.44 \\
\hline Enterococcus spp. & $5(4,1)$ & 0.82 & $1(0,1)$ & 0.79 & 6 & 0.81 \\
\hline Corynebacterium spp. & $4(4,0)$ & 0.66 & 0 & 0.00 & 4 & 0.54 \\
\hline Streptococcus spp. & $6(3,3)$ & 0.98 & $8(3,5)$ & 6.30 & 14 & 1.9 \\
\hline Aerococcus spp. & $5(3,2)$ & 0.82 & 0 & 0.00 & 5 & 0.68 \\
\hline Others & $42(26,16)$ & 6.89 & $10(2,8)$ & 7.87 & 52 & 7.06 \\
\hline Gram-negative organisms & $132(103,29)$ & 21.64 & $39(11,28)$ & 30.71 & 171 & 23.2 \\
\hline Pseudomonas spp. & $56(51,5)$ & 9.18 & $5(2,3)$ & 3.94 & 61 & 8.28 \\
\hline Burkholderia spp. & $10(8,2)$ & 1.64 & 0 & 0.00 & 10 & 1.36 \\
\hline Acinetobacter spp. & $10(6,4)$ & 1.64 & $1(0,1)$ & 0.79 & 11 & 1.49 \\
\hline Escherichia spp. & $6(5,1)$ & 0.98 & $3(2,1)$ & 2.36 & 9 & 1.22 \\
\hline Enterobacter spp. & $6(5,1)$ & 0.98 & $7(2,5)$ & 5.51 & 13 & 1.76 \\
\hline Serratia spp. & $5(4,1)$ & 0.82 & 0 & 0.00 & 5 & 0.68 \\
\hline Chryseobacterium spp. & $3(3,0)$ & 0.49 & 0 & 0.00 & 3 & 0.41 \\
\hline Gardnrella vaginallis & $1(0,1)$ & 0.16 & 0 & 0.00 & 1 & 0.14 \\
\hline Neisseria spp. & $1(0,1)$ & 0.16 & 0 & 0.00 & 1 & 0.14 \\
\hline Xanthomonas spp. & $2(0,2)$ & 0.33 & $3(0,3)$ & 2.36 & 5 & 0.68 \\
\hline Sphingomonas spp. & 0 & 0.00 & $3(0,3)$ & 2.36 & 3 & 0.41 \\
\hline Shigella spp. & 0 & 0.00 & $2(1,1)$ & 1.57 & 2 & 0.27 \\
\hline Others & $32(21,11)$ & 5.25 & $15(4,11)$ & 11.81 & 47 & 6.38 \\
\hline Total & $610(397,213)$ & 100.00 & $127(35,92)$ & 100.00 & 737 & 100 \\
\hline
\end{tabular}

${ }^{*} P<0.05$ : gram-positive isolates between external and intraocular infections (95\% CI: 0.41 0.95).

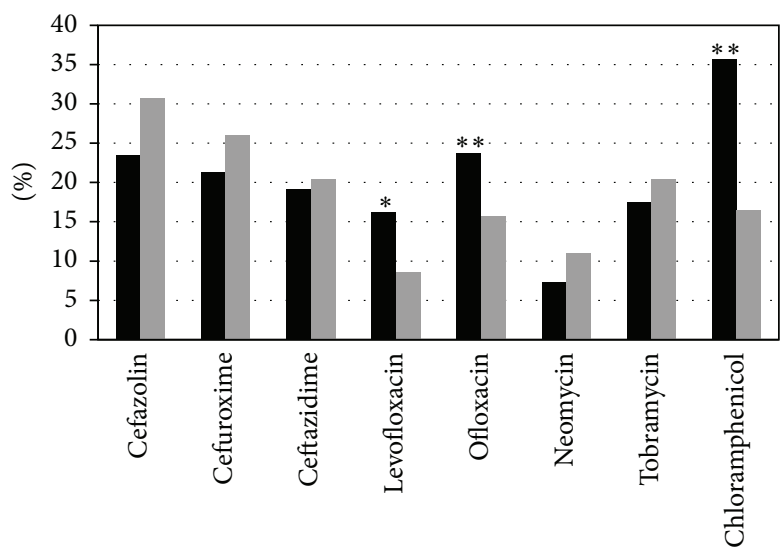

External ocular isolate Intraocular isolate

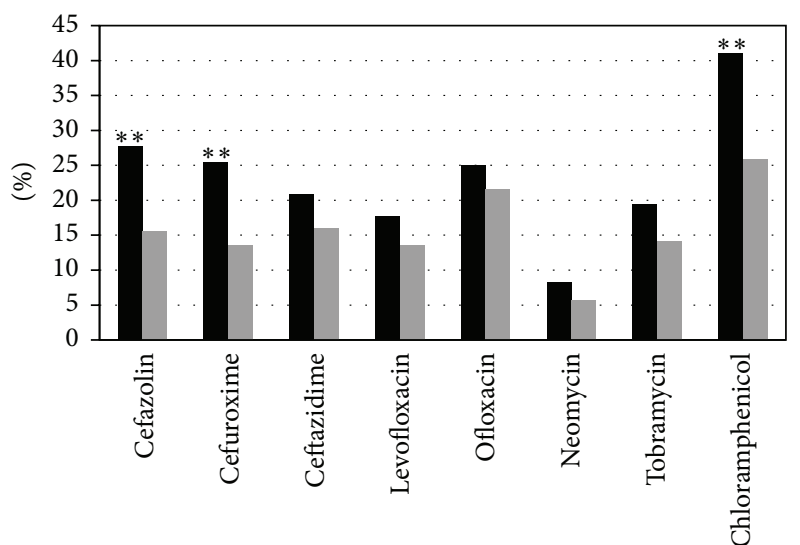

Keratitis

Conjunctivitis

(a)

(b)

FIGURE 1: The drug-resistance of bacteria isolates from different ocular tissues to eight antibiotics. (a) Comparison of external ocular (black) and intraocular (gray) bacteria isolates; (b) comparison of cornea (black) and conjunctiva (gray) isolates. ${ }^{*} P<0.05,{ }^{* *} P<0.01$.

external and intraocular infections showed no significant differences compared to these eight antibiotics. The comparison of the antibiotic resistance of cornea and conjunctiva bacteria isolates to eight antibiotics was shown in Figure 1(b). On the whole, cornea bacteria isolates exhibited significantly higher resistance to cefazolin, cefuroxime, and chloramphenicol as compared to conjunctival isolates $(P<0.01)$.

Additionally, multidrug resistance (MDR) bacterial species were found. We found 89 (12.08\%) MDR bacteria; those were resistant to at least one agent in each of three or 
TABLE 2: Comparison of MDR bacteria between external and intraocular infections.

\begin{tabular}{|c|c|c|c|c|}
\hline & \multicolumn{2}{|c|}{ External ocular infection } & \multicolumn{2}{|c|}{ Intraocular infection } \\
\hline & Cornea & Conjunctiva & Aqueous humor & Vitreous fluid \\
\hline S. epidermidis & 13 (119) & $7(96)$ & $0(5)$ & $0(14)$ \\
\hline P. aeruginosa & $9(45)$ & $0(4)$ & $1(2)$ & $0(1)$ \\
\hline B. cepacia & $6(8)$ & $1(2)$ & $0(0)$ & $0(0)$ \\
\hline S. hominis & $4(19)$ & $1(8)$ & $0(5)$ & $0(6)$ \\
\hline E. coli & $3(5)$ & $0(1)$ & $0(2)$ & $0(1)$ \\
\hline S. auricularis & $3(14)$ & $0(5)$ & $0(1)$ & $0(2)$ \\
\hline$K$. roseus & $3(11)$ & $0(3)$ & $0(0)$ & $2(2)$ \\
\hline S. simulans & $3(17)$ & $0(10)$ & $0(1)$ & $0(1)$ \\
\hline S. haemolyticus & $3(15)$ & $2(5)$ & $0(0)$ & $0(6)$ \\
\hline S. warneri & $3(14)$ & $0(6)$ & $0(0)$ & $0(3)$ \\
\hline E. faecalis & $2(2)$ & $1(1)$ & $0(0)$ & $0(1)$ \\
\hline A. junii & $2(2)$ & $0(2)$ & $0(0)$ & $0(1)$ \\
\hline A. baumannii & $1(2)$ & $0(1)$ & $0(0)$ & $0(0)$ \\
\hline K. varians & $1(3)$ & $0(0)$ & $0(0)$ & $0(0)$ \\
\hline P. putida & $1(2)$ & $0(0)$ & $0(0)$ & $0(0)$ \\
\hline Methylobacterium & $1(2)$ & $0(0)$ & $0(0)$ & $0(0)$ \\
\hline K. kristinae & $1(7)$ & $1(3)$ & $0(1)$ & $0(1)$ \\
\hline Moraxella lacunata & $0(3)$ & $1(4)$ & $0(0)$ & $0(0)$ \\
\hline P. stutzeri & $1(2)$ & $0(1)$ & $0(0)$ & $0(2)$ \\
\hline E. cloacae & $1(3)$ & $0(0)$ & $0(2)$ & $2(4)$ \\
\hline Stenotrophomonas maltophilia & $0(0)$ & $1(2)$ & $0(0)$ & $1(3)$ \\
\hline S. thoraltensis & $0(0)$ & $0(0)$ & $0(0)$ & $1(1)$ \\
\hline Vibrio alginolyticus & $0(0)$ & $0(0)$ & $0(0)$ & $1(1)$ \\
\hline S. lentus & $0(6)$ & $4(10)$ & $0(1)$ & $0(2)$ \\
\hline N. gonorrhoeae & $0(0)$ & $1(1)$ & $0(0)$ & $0(0)$ \\
\hline Total number & 61 & 20 & 1 & 7 \\
\hline Percentage $(\%)^{*}$ & & & & \\
\hline
\end{tabular}

${ }^{*} P<0.05$ external versus intraocular infection (95\% CI: 0.20 0.91).

TABLE 3: The numbers of MDR strains resistant to eight antibiotics.

\begin{tabular}{lcccccccc}
\hline & Cefazolin & Cefuroxime & Ceftazidime & Levofloxacin & Ofloxacin & Neomycin & Tobramycin & Chloramphenicol \\
\hline Keratitis & $33(10,23)$ & $33(11,22)$ & $28(22,6)$ & $35(22,13)$ & $46(31,15)$ & $22(13,9)$ & $40(23,17)$ & $54(30,24)$ \\
Conjunctivitis & $7(5,2)$ & $8(7,1)$ & $13(12,1)$ & $9(7,2)$ & $13(11,2)$ & $6(6,0)$ & $13(10,3)$ & $17(14,3)$ \\
Endophthalmitis & $6(2,4)$ & $5(1,4)$ & $5(3,2)$ & $3(2,1)$ & $5(3,2)$ & $3(1,2)$ & $6(3,3)$ & $6(1,5)$ \\
Total & $46(17,29)$ & $46(19,27)$ & $46(37,9)$ & $47(31,16)$ & $64(45,19)$ & $31(20,11)$ & $59(36,23)$ & $77(45,32)$ \\
\hline
\end{tabular}

${ }^{*}$ MDR number (gram-positive, gram-negative strains).

more antibacterial categories (in our study, cephalosporins, quinolones, aminoglycosides, and phenicols) (Table 2). Of these, the percentage of MDR strains from external and intraocular isolates was $13.28 \%(n=81)$ and $6.30 \%(n=8)$, respectively. The MDR strains of $P$. aeruginosa, $K$. roseus, E. cloacae, and Stenotrophomonas maltophilia were found in both the external and intraocular isolates. However, there were no MDR strains of Staphylococcus spp. in the intraocular infections. Table 3 displayed the raw numbers of MDR strains that were resistant to eight antibiotics. The highest resistance rate of MDR strains was seen for chloramphenicol (86.53\%, 77/89), including 88.52\% (54/61) in keratitis, $85 \%(17 / 20)$ in conjunctivitis, and 75\% (6/8) in endophthalmitis.

\section{Discussion}

The identification of causative pathogens and antibiotic susceptibility tests are important in clinical practice. Our study revealed that the major causative pathogens for both external and intraocular infections were Staphylococcus spp., specifically $61.64 \%$ for external and $43.31 \%$ for intraocular infection. Furthermore, we also found that $P$. aeruginosa, the second most common pathogen for ocular surface $(8.03 \%)$, 
was less frequently detected in the aqueous humor (5.71\%) and vitreous fluid $(0.24 \%)$. Studies conducted by Bharathi et al. in India reported that the most common bacterial species were different among infections of eyelid, conjunctiva, cornea, lacrimal apparatus, and intraocular tissue, of which S. pneumoniae (35.9\%) were the predominant bacteria of infective keratitis in India $[5,20,21]$. In Northeastern United States, Chen and Adelman reported that, among 143 culture-positive isolates, the most prevalent bacteria causing endophthalmitis were coagulase-negative Staphylococcus (37.5\%), Viridans Streptococcus (11.3\%), and Streptococcus pneumoniae (6.9\%) [16]. The difference between their results and those presented in the present study may be due to the variation of geographic location, climate, or contact lens $[20,22]$. Besides, compared to Bharathi et al's study with $58.8 \%$ culture-positive bacteria in 4417 ocular samples [5], we found a lower total culture-positivity rate (24.24\%); similar prevalence within China has been reported from Beijing $(28.6 \%, 1339 / 4705)$ [23], Zhejiang $(15.8 \%, 138 / 871)$ [24], and Tianjin $(34.3 \%, 1119 / 3265)$ [25], which may be attributable to the use of antibiotics, obtained from a local physician or a drug store, before patient came to our hospital, or overdiagnose cases of "red eye" as bacterial conjunctivitis and keratitis.

In our study, 8 antibiotics belonging to four categories (cephalosporins, quinolones, aminoglycosides, and phenicols) were tested for resistance. The antibiotic susceptibility analysis showed variation between external and intraocular isolates: the bacteria from the ocular surface were more sensitive to neomycin, while the intraocular isolates presented higher sensitivity to levofloxacin. These results are different from those of a study from Bangalore, in which Hemavathi and colleagues reported that the organisms from both external and intraocular isolates were susceptible to quinolone antibiotics [6]. Considering that eye drops with quinolones (levofloxacin, ofloxacin) and aminoglycosides (neomycin, tobramycin) are the major eye drop products in the Chinese market, the present data will aid in choosing eye drops for ocular surface infections. Though eye drops containing ceftazidime are not commercially available because of its rapid degradation in aqueous solutions, for serious intraocular infections such as suppurative endophthalmitis, systemic or intraocular application of antibiotics (e.g., ceftazidime) is necessary. Studies showed that recent trends have shifted to using ceftazidime, instead of aminoglycosides that have toxic role in macula, to treat endophthalmitis infected with gram-negative bacteria [12, 26, 27]. Our current result showed that intraocular isolates had a high sensitivity to ceftazidime, which could be a better choice for intraocular application. Additionally, studies on the optimization of liposomal encapsulation for developing a potential eye drop formulation of ceftazidime have been reported $[28,29]$, which may provide more effective treatment for ocular infections. No matter external and intraocular infections, our present data will help clinician make decisions for the choice of antibiotics before definitive information on the causative pathogenic microorganisms is available. MDR organisms have been recently defined as those that are resistant to at least one agent in each of three or more antibacterial categories, introduced by the European Centre for Disease Prevention and Control in 2012 [30]. Following this new definition, the total rate of MDR strains was $12.08 \%$ in our study, wherein the rate of MDR S. epidermidis and $P$. aeruginosa accounted for approximately $22.47 \%$ and $11.24 \%$, respectively. By defining MDR to two or more drugs, Muluye et al. reported that $87.1 \%$ of isolates showed MDR among 62 bacteria isolated from eye discharge samples [31]. Although it is difficult to compare our MDR results with other reports, MDR bacteria have been shown to be very important in ocular infections in previous studies [31-33]. It has been suggested that the indiscriminate, prolonged use of a wide range of antibiotics may be a major factor in the development of drug resistance [34]. The combined use of antibiotics could provide broader coverage against infection prior to susceptibility testing.

In conclusion, we found that the bacteria profile of external and intraocular infections varied in the setting of our study. In the comparison of eight antibiotics, the bacteria from external ocular samples were more sensitive to neomycin, while intraocular isolates were significantly more sensitive to levofloxacin than to neomycin. A higher MDR appeared in ocular surface isolates. It should be noted that there were still some limitations in our study, such as the limited kinds of antibiotics, the relatively lower intraocular species, and the fact that the results of culture-positive and antibiotic susceptibility in vitro do not always agree with clinical observations. The in vitro results are dependent on the protocol of sample collection and inoculation, as well as primary treatment before sample collection.

\section{Conflict of Interests}

There is no commercial conflict of interests or any other conflict of interests in this paper.

\section{Acknowledgments}

This research was supported in part by funds from the Doctoral Program of Higher Education, Ministry of Education, and the Key Laboratory of Ophthalmology, Guangdong, China.

\section{References}

[1] M. D. P. Willcox, "Characterization of the normal microbiota of the ocular surface," Experimental Eye Research, vol. 117, pp. 99-105, 2013.

[2] Q. Dong, J. M. Brulc, A. Iovieno et al., "Diversity of bacteria at healthy human conjunctiva," Investigative Ophthalmology and Visual Science, vol. 52, no. 8, pp. 5408-5413, 2011.

[3] M. R. Chalita, A. L. Höfling-Lima, A. Paranhos Jr., P. Schor, and R. Belfort Jr., "Shifting trends in in vitro antibiotic susceptibilities for common ocular isolates during a period of 15 years," American Journal of Ophthalmology, vol. 137, no. 1, pp. 43-51, 2004.

[4] Y. Shimizu, H. Toshida, R. Honda et al., "Prevalence of drug resistance and culture-positive rate among microorganisms isolated from patients with ocular infections over a 4-year period," Clinical Ophthalmology, vol. 7, pp. 695-702, 2013. 
[5] M. J. Bharathi, R. Ramakrishnan, C. Shivakumar, R. Meenakshi, and D. Lionalraj, "Etiology and antibacterial susceptibility pattern of community-acquired bacterial ocular infections in a tertiary eye care hospital in south India," Indian Journal of Ophthalmology, vol. 58, no. 6, pp. 497-507, 2010.

[6] Hemavathi, P. Sarmah, and P. Shenoy, "Profile of microbial isolates in ophthalmic infections and antibiotic susceptibility of the bacterial isolates: a study in an eye care hospital, Bangalore," Journal of Clinical and Diagnostic Research, vol. 8, no. 1, pp. 23$25,2014$.

[7] A. Adebayo, J. G. Parikh, S. A. McCormick et al., "Shifting trends in in vitro antibiotic susceptibilities for common bacterial conjunctival isolates in the last decade at the New York Eye and Ear Infirmary," Graefe's Archive for Clinical and Experimental Ophthalmology, vol. 249, no. 1, pp. 111-119, 2011.

[8] C. Blanco and M. X. Núñez, "Antibiotic susceptibility of staphylococci isolates from patients with chronic conjunctivitis: including associated factors and clinical evaluation," Journal of Ocular Pharmacology and Therapeutics, vol. 29, no. 9, pp. 803808, 2013.

[9] F. E. Abdullah, M. I. Khan, and S. Waheed, "Current pattern of antibiotic resistance of clinical isolates among conjunctival swabs," Pakistan Journal of Medical Sciences, vol. 29, no. 1, pp. 81-84, 2013.

[10] F. Giardini, G. Grandi, U. De Sanctis et al., "In vitro susceptibility to different topical ophthalmic antibiotics of bacterial isolates from patients with conjunctivitis," Ocular Immunology and Inflammation, vol. 19, no. 6, pp. 419-421, 2011.

[11] B. Mshangila, M. Paddy, H. Kajumbula, C. Ateenyi-Agaba, B. Kahwa, and J. Seni, "External ocular surface bacterial isolates and their antimicrobial susceptibility patterns among preoperative cataract patients at Mulago National Hospital in Kampala, Uganda," BMC Ophthalmology, vol. 13, article 71, 2013.

[12] S. Sharma, T. R. Padhi, S. Basu, S. Kar, A. Roy, and T. Das, "Endophthalmitis patients seen in a tertiary eye care centre in Odisha: a clinico-microbiological analysis," Indian Journal of Medical Research, vol. 139, pp. 91-98, 2014.

[13] M. S. Benz, I. U. Scott, H. W. Flynn Jr., N. Unonius, and D. Miller, "Endophthalmitis isolates and antibiotic sensitivities: a 6-year review of culture-proven cases," American Journal of Ophthalmology, vol. 137, no. 1, pp. 38-42, 2004.

[14] T. L. Jackson, S. J. Eykyn, E. M. Graham, and M. R. Stanford, "Endogenous bacterial endophthalmitis: a 17-year prospective series and review of 267 reported cases," Survey of Ophthalmology, vol. 48, no. 4, pp. 403-423, 2003.

[15] M. Green, A. Apel, and F. Stapleton, "A longitudinal study of trends in keratitis in Australia," Cornea, vol. 27, no. 1, pp. 33-39, 2008.

[16] X. Chen and R. A. Adelman, "Microbial spectrum and resistance patterns in endophthalmitis: a 21-year (1988-2008) review in Northeast United States," Journal of Ocular Pharmacology and Therapeutics, vol. 28, no. 4, pp. 329-334, 2012.

[17] C. Long, B. Liu, C. Xu, Y. Jing, Z. Yuan, and X. Lin, "Causative organisms of post-traumatic endophthalmitis: a 20 -year retrospective study," BMC Ophthalmology, vol. 14, article 34, 2014.

[18] Y. Ding, M. Lin, H. Liu, W. Zhang, L. Wang, and Y. Li, "Outcomes of post-cataract surgery endophthalmitis referred to a tertiary center from local hospitals in the south of China," Infection, vol. 39, no. 5, pp. 451-460, 2011.
[19] T. Bourcier, F. Thomas, V. Borderie, C. Chaumeil, and L. Laroche, "Bacterial keratitis: predisposing factors, clinical and microbiological review of 300 cases," British Journal of Ophthalmology, vol. 87, no. 7, pp. 834-838, 2003.

[20] M. J. Bharathi, R. Ramakrishnan, R. Meenakshi, S. Padmavathy, C. Shivakumar, and M. Srinivasan, "Microbial keratitis in South India: influence of risk factors, climate, and geographical variation," Ophthalmic Epidemiology, vol. 14, no. 2, pp. 61-69, 2007.

[21] M. J. Bharathi, R. Ramakrishnan, S. Vasu, R. Meenakshi, C. Shivkumar, and R. Palaniappan, "Epidemiology of bacterial keratitis in a referral centre in south India," Indian Journal of Medical Microbiology, vol. 21, no. 4, pp. 239-245, 2003.

[22] M. Willcox, S. Sharma, T. J. Naduvilath, P. R. Sankaridurg, U. Gopinathan, and B. A. Holden, "External ocular surface and lens microbiota in contact lens wearers with corneal infiltrates during extended wear of hydrogel lenses," Eye and Contact Lens, vol. 37, no. 2, pp. 90-95, 2011.

[23] W. Sun, Z. Wang, L. Chen, S. Luo, X. Jin, and W. Zhang, "Etiological analysis on bacterial ocular disease in northern China (1989-1998)," Chinese Medical Journal, vol. 115, no. 6, pp. 933-935, 2002.

[24] X. Mao, M. Zheng, D. Chen et al., "Monitoring of antimicrobial resistance of pathogens causing nosocomial infections in ophthalmic hospital," Chinese Journal of Nosocomiology, vol. 23, no. 17, pp. 4315-4317, 2013.

[25] Y. Li, "Microbial spectrum and resistance patterns of ocular infection in Tianjin Eye Hospital (2005-2009)," Shandong Medicine, vol. 50, no. 35, pp. 65-66, 2010.

[26] P.-L. Cornut and C. Chiquet, "Intravitreal injection of antibiotics in endophthalmitis," Journal Francais d'Ophtalmologie, vol. 31, no. 8, pp. 815-823, 2008.

[27] M. Çakir, O. Çekiç, G. Pekel, and Ö. F. Yilmaz, "Pars plana vitrectomy results of exogenous endophthalmitis in children," European Journal of Ophthalmology, vol. 20, no. 2, pp. 424-428, 2010.

[28] C. Wijesooriya, M. Budai, L. Budai, M. E. Szilasi, and I. Petrikovics, "Optimization of liposomal encapsulation for ceftazidime for developing a potential eye drop formulation," Journal of Basic and Clinical Pharmacy, vol. 4, no. 3, pp. 73-75, 2013.

[29] I. M. S. Torres, E. B. Bento, L. D. C. Almeida, L. Z. C. M. de Sá, and E. M. Lima, "Preparation, characterization and in vitro antimicrobial activity of liposomal ceftazidime and cefepime against Pseudomonas aeruginosa strains," Brazilian Journal of Microbiology, vol. 43, no. 3, pp. 984-992, 2012.

[30] A.-P. Magiorakos, A. Srinivasan, R. B. Carey et al., "Multidrugresistant, extensively drug-resistant and pandrug-resistant bacteria: an international expert proposal for interim standard definitions for acquired resistance," Clinical Microbiology and Infection, vol. 18, no. 3, pp. 268-281, 2012.

[31] D. Muluye, Y. Wondimeneh, F. Moges, T. Nega, and G. Ferede, "Types and drug susceptibility patterns of bacterial isolates from eye discharge samples at Gondar University Hospital, Northwest Ethiopia," BMC Research Notes, vol. 7, article 292, 2014.

[32] S. Mehta, H. Mansoor, S. Khan, P. Saranchuk, and P. Isaakidis, "Ocular inflammatory disease and ocular tuberculosis in a cohort of patients co-infected with HIV and multidrugresistant tuberculosis in Mumbai, India: a cross-sectional study," BMC Infectious Diseases, vol. 13, article 225, 2013. 
[33] R. Jain, S. I. Murthy, and S. R. Motukupally, "Clinical outcomes of corneal graft infections caused by multi-drug resistant Pseudomonas aeruginosa," Cornea, vol. 33, no. 1, pp. 22-26, 2014.

[34] B. D. Gaynor, J. D. Chidambaram, V. Cevallos et al., "Topical ocular antibiotics induce bacterial resistance at extraocular sites," British Journal of Ophthalmology, vol. 89, no. 9, pp. 10971099, 2005. 


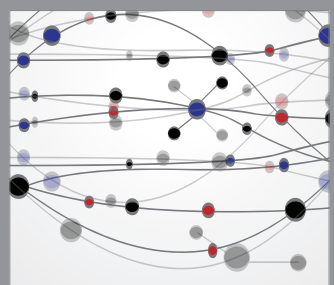

The Scientific World Journal
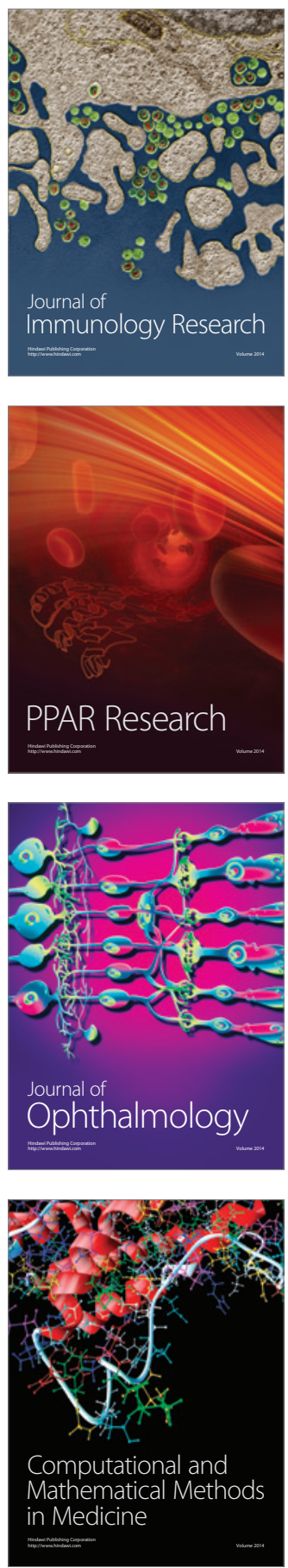

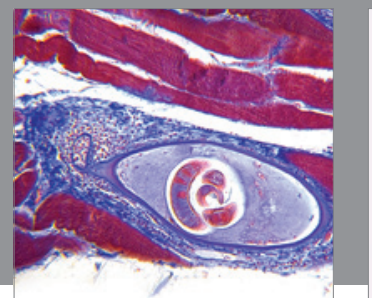

Gastroenterology

Research and Practice
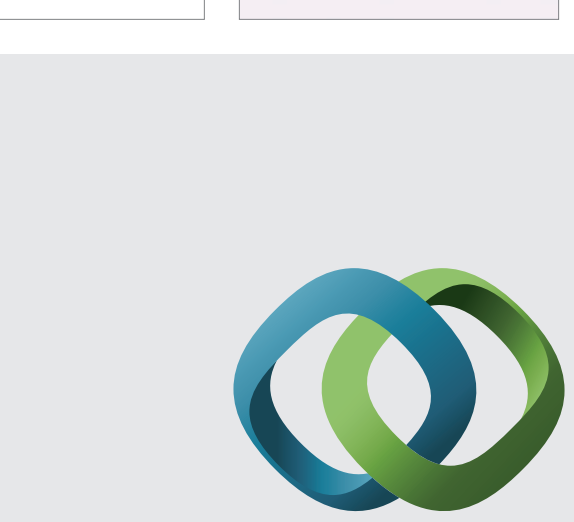

\section{Hindawi}

Submit your manuscripts at

http://www.hindawi.com
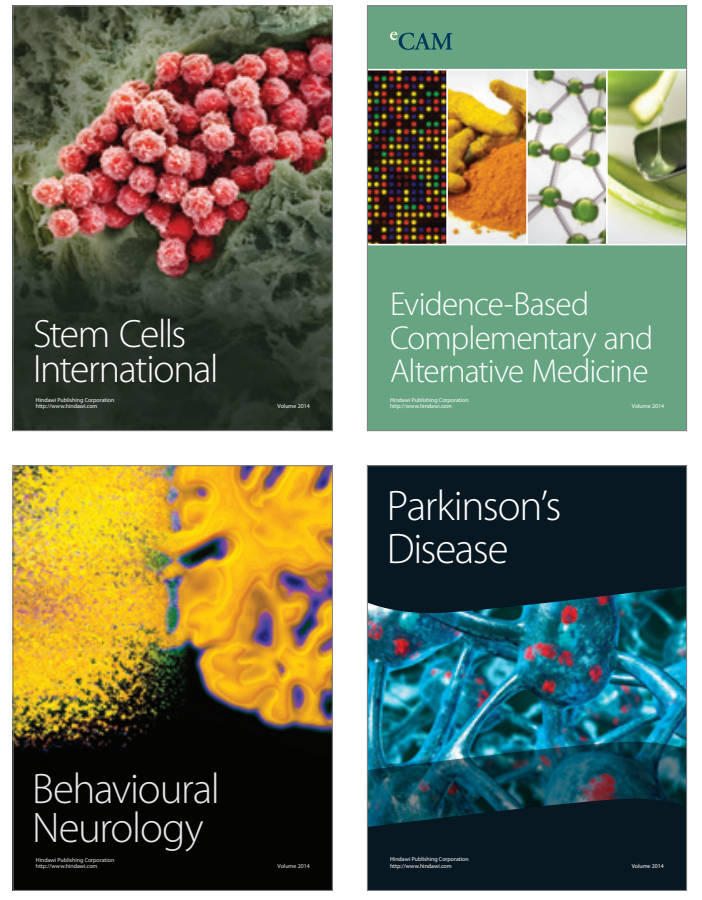
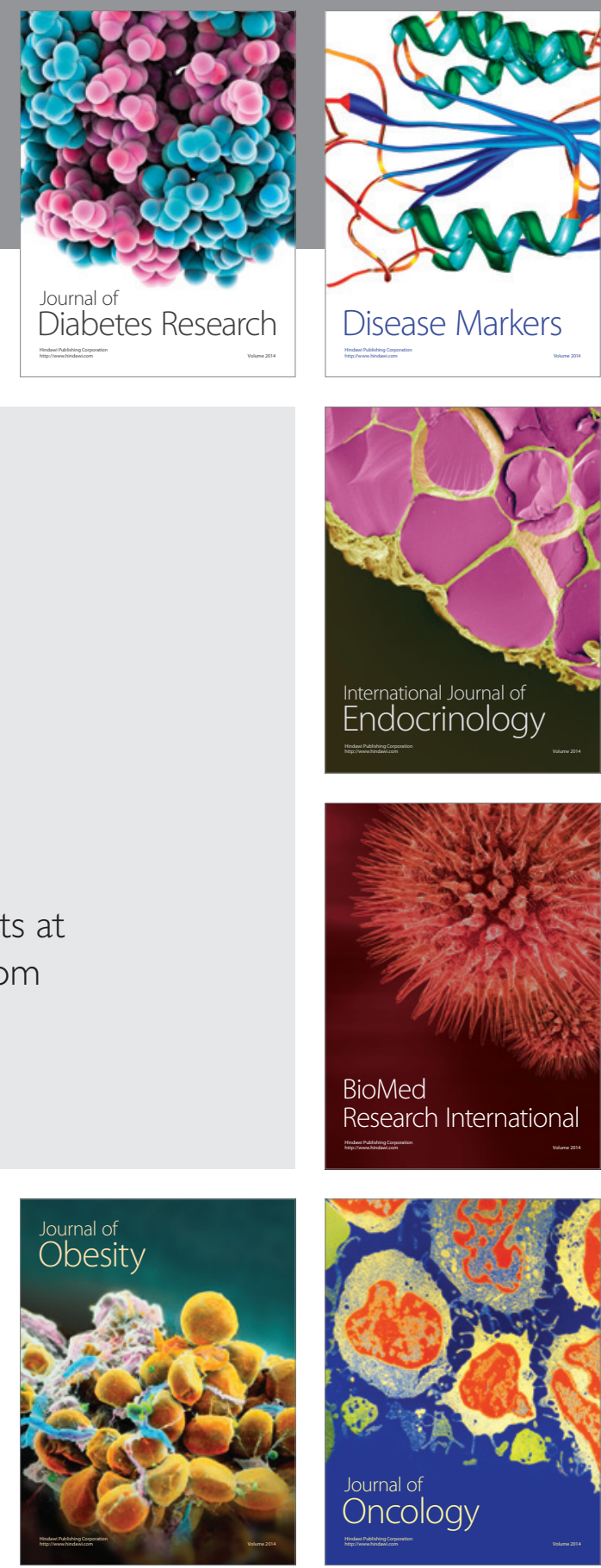

Disease Markers
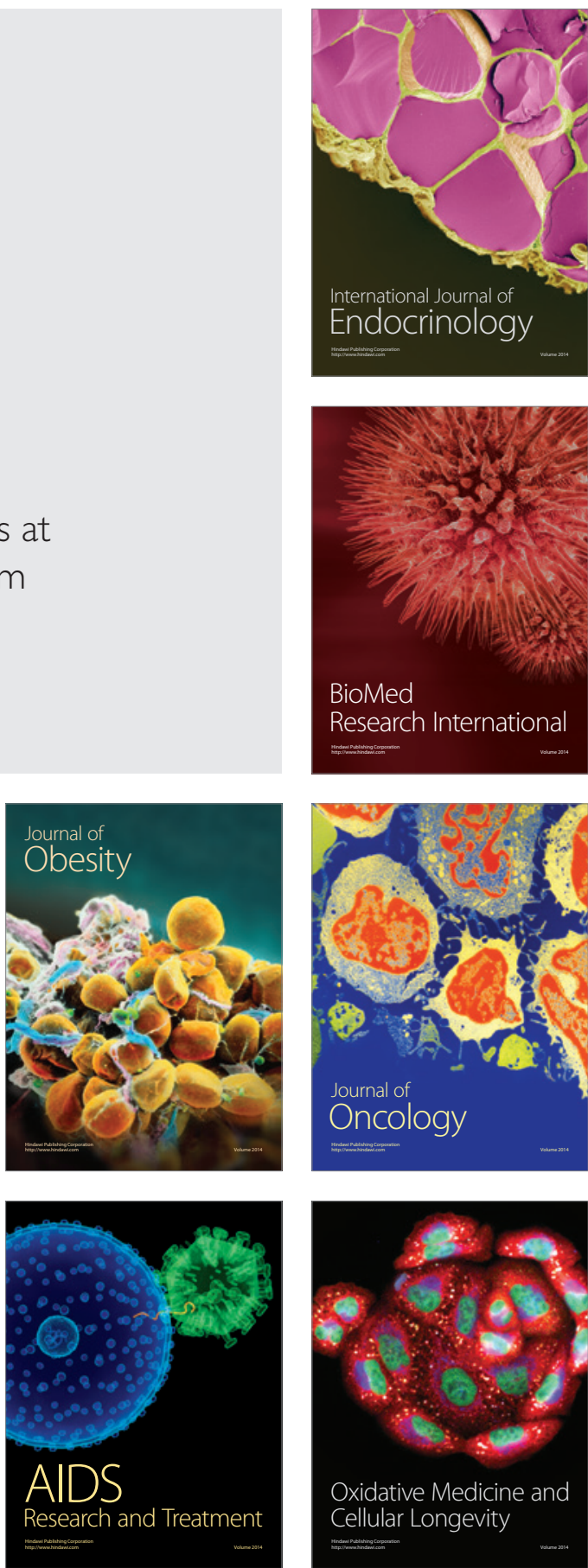